\title{
Aplicação da desconsideração da personalidade jurídica nos crimes ambientais: o caso do Rio Doce
}

\author{
Vital José Pessoa Madruga Filho*, José Ronildo Souza da Silva, \\ Hélder Formiga Fernandes
}

Universidade Federal da Paraíba. Centro de Ciências Exatas e da Natureza. Programa de Pós-Graduação em Desenvolvimento e Meio Ambiente. Campus I. João Pessoa-PB, Brasil (CEP 58051-900).*E-mail: vitalpessoa@bol.com.br.

Resumo. Diante dos múltiplos e mais variados danos ambientais experimentados pela comunidade internacional, motivados pelos avanços inconsequentes e desenfreados do mercado de capitais, impulsionado pelo consumismo desmedido, tem-se que as empresas (pessoas jurídicas) são os grandes responsáveis por enormes impactos socioambientais, cujos delitos são suportados pelas presentes e futuras gerações. Portanto, é preciso punir os responsáveis pelas nocivas degradações ambientais, que nos últimos tempos vitimou o Rio Doce, cujos impactos ultrapassam a questão meramente ambiental, e atingem os espectros sociais e econômicos.

Palavras-chaves: Direito Ambiental; Impacto socioambiental; Pessoa jurídica; Personalidade jurídica.

Abstract. Application of disregard of legal personality in environmental crimes: The case of Rio Doce. In view of the multiple and more varied environmental damages experienced by the international community, motivated by the inconsequential and uncontrolled advances of the capital market, driven by excessive consumerism, companies (legal entities) are responsible for enormous socio-environmental impacts, whose crimes are borne by present and future generations. Therefore, it is necessary to punish those responsible for the harmful environmental degradation, which in recent times has victimized the Rio Doce, whose impacts surpass the merely environmental issue, and reach the social and economic specters.

Keywords: Environmental Law; Socio-environmental impact; Legal person; Legal personality.

Recebido: 06/08/2018

Aceito:

$27 / 08 / 2018$

Publicado:

$31 / 08 / 2018$

Acesso aberto

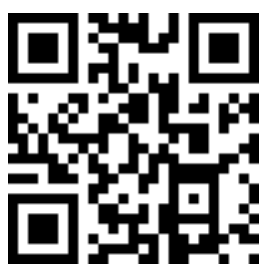

ORCID

D 0000-0002-0351-9807

Vital José Pessoa

Madruga Filho

(1) 0000-0002-3202-5267

José Ronildo Souza da Silva

(D) 0000-0002-0370-0673

Hélder Formiga

Fernandes

\section{Introdução}

A doutrina da desconsideração da pessoa jurídica nasceu na Inglaterra em 1896, no famoso caso de Salomon versus Salomon Company. Esse precedente deu origem à disregar doctrine, que foi desenvolvida na Alemanha, com o jurista Rolf Serick, professor da Universidade de Heidenberg, e, no Brasil, foi introduzida pelo Professor Rubens Requião.

Tal teoria tem o objetivo de não considerar os efeitos da personificação para poder encaminhar à responsa- 
bilidade dos sócios. Por isso, é também denominada como doutrina da penetração.

O famoso conceito de personalidade jurídica é a qualidade para ser sujeito de direito. 0 conceito técnico de personalidade, por sua vez, seria a aptidão genérica para fundamentar direitos e contrair obrigações na ordem jurídica. Destarte, são sujeitos de direito a pessoa física ou natural e a pessoa jurídica.

O princípio da autonomia patrimonial, que caracteriza a pessoa jurídica, muitas vezes funciona como elemento fomentador do cometimento de abusos por parte dos sócios que a compõem. Contudo, a teoria desconsideração da pessoa jurídica não visa a anular, nem mesmo a mitigar, o princípio da autonomia da pessoa jurídica, mas sim reforçá-la. Busca-se, dessa maneira, promover a compatibilidade da pessoa jurídica com a economia do país, tentando obstruir as fraudes e os abusos praticados por uso inadequado da pessoa jurídica.

Explica, o presente artigo, o desvio de finalidade e a confusão patrimonial como duas formas de abuso da personalidade jurídica. Frise-se, no entanto, que a desconsideração significa a ineficiência relativa da pessoa jurídica na relação obrigacional, enquanto que, para as outras finalidades, a personalidade jurídica da entidade continua incólume.

A desconsideração da personalidade jurídica inversa, no direito ambiental, ocorre quando, ao aplicaremse os princípios da precaução e da prevenção de danos ambientais, existe a possibilidade de os responsáveis pela pessoa jurídica terem seus bens particulares atingidos, respondendo pela ocorrência do dano ao meio ambiente. Busca-se, desse modo, fazer com que o respeito ao meio ambiente equilibrado tenha repercussão, promovendo-se 0 ressarcimento ou a compensação dos danos.
0 presente artigo tem por objetivo estudar o caso da mineradora Samarco $(50 \%$ da brasileira Vale e $50 \%$ da Anglo-Australiana BHP Billiton), que após o rompimento da Barragem do Fundão, vilas inteiras foram devastadas pela lama tóxica. Posteriormente, o Rio Doce foi atingido e consequentemente, meio milhão de pessoas ficaram sem o fornecimento de água potável no Estado de Minas Gerais, além da poluição do litoral Oceano Atlântico na Costa do Estado do Espírito Santo, ambos no Brasil.

Para realização da presente investigação, fez-se necessária a aplicação do método dogmático, com a hermenêutica que os textos normativos recomendam. Foram necessários, de igual modo, o aporte à doutrina e à transversalidade, uma vez que se trata de tema interdisciplinar de elevado teor político e sociológico, alinhavado por uma tradição de pensamento racionalista da analise jurisprudencial.

Por derradeiro, a investigação representa um convite ao leitor interessado em saber mais sobre a teoria da desconsideração da pessoa jurídica, quais os dispositivos legais que lhe dão legitimidade, o posicionamento da jurisprudência brasileira e, finalmente, como a doutrina e os tribunais vêm aplicando esta teoria em sua modalidade inversa no âmbito do direito ambiental, especialmente no que tange aos crimes ambientais.

\section{Teorias da desconsideração da pessoa jurídica}

Requião (1989), defendia que essa teoria tem o objetivo de não considerar os efeitos da personificação para que seja possível chegar à responsabilidade dos sócios. Isso acontece quando o sócio da empresa age de maneira ilícita e busca responsabilizar a pessoa jurídica por seus atos; por essa razão, a teoria é também denominada doutrina da penetração. Ainda consoante Requião, a teoria não busca anular a 
personificação da pessoa jurídica, mas sim torná-la ineficaz para alguns atos:

\begin{abstract}
Recentemente, porém, tendo em vista as fraudes promovidas através da personalização de sociedade anônimas, seja em problemas de âmbito privado, seja em relações de direito público, se foi elaborando por construção jurisprudencial uma doutrina para coibir os abusos verificados. Surgiu, assim, a doutrina do Disregard of Legal Entily no direito anglo-saxão, espraiando-se para o direito germânico e mais recentemente repercutindo na literatura jurídica da Itália. Esse palpitante assunto merece uma análise especial, pois será inevitável sua influência em nosso moderno direito societário (Requião, 1989, p. 283).
\end{abstract}

Comparato (2003) destaca que, surgida na Alemanha em tese apresentada pelo professor da Universidade de Heidelberg, Rolf Serick, como nome de disregard doctrine, a teoria da desconsideração da pessoa jurídica foi inicialmente estudada no Brasil por Requião (1989), e foram seus estudos que influenciaram Miguel Reale a instituir essa teoria na Comissão Revisora do Código Civil. Conforme Ulhoa (2002), "a teoria foi criada por doutrinas e varias jurisprudências dos EUA, Inglaterra e Alemanha culminando por dar ensejo a elaboração da "Teoria da Desconsideração da Pessoa Jurídica".

Depreende-se das lições de Ramos (2010) que a desconsideração da pessoa jurídica ocorre quando há a constatação de abusos e fraude da personalidade jurídica. Estes surgem com a má utilização da autonomia patrimonial, buscando-se benefícios ocasionados pela separação patrimonial dos bens dos sócios e da sociedade para fraudar credores e proteger seus patrimônios pessoais.

Pertinente o esclarecimento trazido pelo supramencionado autor ao citar Rolf Serick, cuja tese afirma que: "a doutrina tem aplicado no terreno do direito tributário, para inibir a sonegação e evasão de impostos, quando se usa a personalidade da sociedade comercial como anteparo". E conclui que dois casos, na jurisprudência, foram importantes para o início da doutrina:

1 - Bank of United States vs. Deveaux (corte americana);

2 - Caso julgado em 1896 (Salomon vs Salomon Co.) (Inglaterra). Salomon quis constituir uma companhia. e elaborou um contrato social no qual ele tinha $99 \%$ das ações. Essa sociedade começou a atuar no mercado, angariando dívidas. Para tentar se salvar, Salomon começou a emitir títulos no mercado, que foram comprados por ele mesmo, passando a ser o primeiro da fila no recebimento dos créditos. Os demais credores alegaram que Salomon usou da pessoa jurídica para fins de fraude (Serick, 1958).

Neste contexto, Requião (1989) frisa, como exemplo do cometimento de ações que ensejam a aplicação da teoria estudada, a transferência fraudulenta dos bens do devedor para o capital de uma pessoa jurídica, o qual objetiva ocasionar prejuízo a terceiros.

Impende destacar, ainda, que um tribunal, ao aplicar a teoria da desconsideração da pessoa jurídica, não coloca em cheque a diferença de personalidade entre a empresa e seus sócios, procura apenas dificultar a consumação dessas fraudes e abusos de direitos feitos através da personalidade jurídica.

Também, sobre o tema, lúcida de Serick (1958), cujas palavras, transcrevem-se a seguir:

Não temos dúvida que a doutrina, pouco divulgada em nosso País, levada à consideração de nossos tribunais, poderia ser perfeitamente 
adotada, para impedir a consumação de fraude contra credores e mesmo contra o fisco, tendo como escudo a personalidade jurídica da sociedade comercial. (Serick, 1958)

Como pontua Tepedino (2007), é lamentável que essa doutrina não tenha sido bem utilizada no Brasil, principalmente por conta da confusão que $o$ magistrado faz entre a despersonificação e a desconsideração. Essa doutrina difunde o afastamento temporário da personalidade jurídica, quando houver abuso ou fraude, para garantir que os credores lesados recebam seus créditos no patrimônio pessoal dos administradores ou sócios.

Segundo Ramos (2010):

A desconsideração tem seus efeitos adstritos ao caso concreto em que foi requerida, continuando a pessoa juridica - ainda que 'desconsiderada' naquele caso - a existir normalmente e a ter os efeitos da sua personalização respeitados em todas as demais relações jurídicas em que figurar. É por isso que se critica a expresao despersonalização da pessoa jurídica, usada por alguns autores (Ramos, 2010, p. 336).

Ramos (2010, p. 338) conclui que somente "a desconsideração implica, uma suspensão temporária dos efeitos da personalização num determinado caso, não estendendo seus efeitos para as demais relações jurídicas das quais a pessoa jurídica faça parte."

Em consonância com esse pensamento, Tepedino (2007) preleciona as diferenças entre despersonalização e desconsideração da pessoa jurídica. A teoria da despersonificação é consagrada pelo princípio da autonomia patrimonial que norteia a pessoa jurídica, o qual é a principal causa ensejadora do surgimento de fraudes e abusos.

Nahas (2004), por sua vez, preceitua que despersonalizar é anular a personalidade já atribuída à determinada sociedade e, ao citar Marcal Justen Filho, afirma que a personalização é um abuso permitido em lei. Convém esclarecer que a desconsideração não anula a pessoa jurídica, não entrando esta em processo de liquidação. Os efeitos são apenas patrimoniais e pertinentes a obrigações específicas. A título de exemplificação, mencione-se que o ativo maior que o passivo não enseja a aplicação da teoria. Nahas (2004) menciona:
A primeira observação a ser feita é que está equivocado o uso da expressão despersonalização da pessoa jurídica, posto que tal fenômeno não ocorre quando tratarmos da questão ora estudada (da desconsideração). Desperso- nalizar quer dizer retirar a personalidade que lhe foi atribuída, e o que ocorre nas hipóteses aqui tratadas é, dentro do caso concreto, desconsiderar aquela atribuição inicial de personalidade para, dentro de determinados limites, atingir pessoas e bens que se escondem atrás daquela personalidade (Nahas, 2004, p. 146).

Ramos (2010) preceitua a disregard doctrine ao ratificar inúmeras vezes que ocorrerá a desconsideração da pessoa jurídica quando esta for utilizada como meio de burlar a moral e a legalidade, aproveitando-se da separação entre o patrimônio da pessoa física, que constitui a pessoa jurídica, e os bens que a compõem.

Para Diniz (2009), o artigo 1024, do Código Civil consagra o princípio da autonomia patrimonial das pessoas júridicas, sendo um desdobramento do princípio constitucional da livre iniciativa, incentivando o desenvolvimento das empresas.

Podemos constatar, conforme reza a supracitada autora (Diniz, 2009), que os sócios irão responder subsidiariamente pelas dívidas da sociedade. Quando uma determinada sociedade é registrada, começa a ter personalidade jurídica, tornando-se sujeito de direitos e obrigações 
patrimoniais. Devido a isso, os sócios podem agir ilegalmente, buscando auferir lucros. Nesse diapasão, a teoria ora estudada surge com o intento de evitar tal abuso, já que a sociedade sofreu a personificação e possui personalidade diferente da de seus administradores ou sócios.

Nahas (2004) também preleciona acerca dessa questão:

Observe-se que ao estado interessa essa permissão de formação de entes independentes inconfundíveis com a figura humana, principalmente na sociedade capitalista, entendida essa no sentido preconizado por Max Weber. Ou seja, uma sociedade que busca o lucro renovado "por meio da empresa permanente, capitalista e racional" (Nahas, 2004, p. 97)

Ulhoa (2002) assevera que o princípio da autonomia patrimonial pode contribuir para os abusos. Contudo, essa teoria não visa a anular ou pôr em cheque o princípio da autonomia da pessoa jurídica, mas sim reforçá-la, procurando a compatibilidade da importância da pessoa jurídica para a economia do Brasil, tentando obstruir as fraudes e os abusos praticados por uso inadequado da pessoa jurídica. A desconsideração da pessoa jurídica ocorrerá em determinado objeto eivado de fraudes ou abusos, que não produzirá nenhum efeito, o que evita a dissolução ou anulação da sociedade.

Comentado o art. 1.024, do Código Civil, Nery (2009) cita uma jurisprudência do tribunal de justiça de são Paulo:

Fraude à execução. Desconsideração da personalidade jurídica. Se existe prova nos autos de que a empresa devedora vem se utilizando de meios indevidos para frustrar a execução, e inexistindo nos autos elementos que comprovem tenha a empresa outros bens passiveis de penhora, é possível desconsiderar-se sua personalidade jurídica e proceder-se à penhora de bens particulares dos sócios.

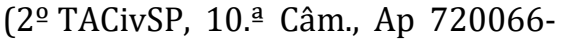
$0 / 1$, rel. Juiz Soares Levada, v.u., j. 28.11.2001) (Nery, 2009).

No mais, Nahas (2004) preleciona a possibilidade de se desconsiderar a personalidade jurídica com o intuito de responsabilizar os sócios ou administradores devido a atos abusivos e desvios de finalidade em nome da pessoa jurídica, uma vez que houve o desfazimento do princípio da boa-fé, princípio de suma importância nas relações societárias.

\section{Abusos da personalidade jurídica}

Gonçalves (2007) afirma que a desconsideração da personalidade jurídica é a possibilidade de levar algumas obrigações da pessoa jurídica para os membros dessa mesma entidade, por conta do uso de meio fraudulento dos administradores e sócios que a compõem. Essa possibilidade existe por conta da independência da pessoa jurídica, que é responsável por seus atos e omissões, independentemente das obrigações suportadas por seus entes.

Neste contexto, Nery (2009) aponta o desvio de finalidade e a confusão patrimonial como duas formas de abuso da personalidade jurídica. A desconsideração significa a ineficiência relativa da pessoa jurídica na relação jurídica, ou seja, para as outras finalidades, a personalidade jurídica da entidade continua incólume.

Desta forma, o mencionado autor aduz que o desvio de finalidade acontece quando a pessoa jurídica pratica atos ilícitos ou incompatíveis com a atividade legal, com o intuito de enriquecimento ilícito de seus sócios, acarretando na possibilidade de ter sua personalidade jurídica desconsiderada. Em contrapartida, há confusão patrimonial quando houver dúvidas de quem é o patrimônio, se dos sócios ou da pessoa jurídica em questão. Com isso, os sócios responderão pelos prejuízos decorrentes 
da não separação do patrimônio do sócio e da pessoa jurídica.

Para Diniz (2009), constatado o abuso na utilização da personalidade jurídica, através de desvio de finalidade ou confusão patrimonial (CC, art. 50), permite-se ao juiz, a pedido da parte interessada - o prejudicado pela conduta ilícita ou do Ministério Público -, desconsiderar a personalidade da empresa, fazendo cessar a sua autonomia patrimonial, possibilitando a penhora de bens particulares dos membros, submetendo os sócios a um processo judicial, depois da comprovação da insolvência da pessoa jurídica. Sendo assim, a desconsideração advém do uso irregular, ou seja, fraudulento da pessoa jurídica.

A primeira Jornada de Direito Civil, do centro de estudos judiciários do Conselho da Justiça Federal, aprovou o Enunciado Número 7 referente à desconsideração da personalidade jurídica, in verbis:

7 - Art. 50. Só se aplica a desconsideração da personalidade jurídica quando houver a prática de ato irregular, e, limitadamente, aos administradores ou sócios que nela hajam incorrido (Aguiar Junior, 2003, p. 51).

A terceira Jornada de Direito Civil, por seu turno, aprovou o enunciado de número 146, in verbis:

146 - Art. 50: Nas relações civis, interpretam-se restritivamente os parâmetros de desconsideração da personalidade jurídica previstos no art. 50 (desvio de finalidade social ou confusão patrimonial) (Aguiar Junior, 2007, p. 103).

Segundo Nery Junior (2009), a comparação para poder aplicar a teoria está relacionada à administração, com desvio de finalidade ou confusão patrimonial. Assim, o patrimônio dos membros é que vai responder pelas irregularidades, não se exigindo nenhum prazo processual específico para aplicação da teoria. Convém salientar que é o próprio art. 50, do Código Civil que fala do desvio ou confusão.

Para Tepedino (2007), a redação dos dispositivos no Código Civil de 2002 trata de maneira exorbitante a idéia de abuso, diferentemente de outras leis que abordam o mesmo tema. 0 bem jurídico tutelado por essa teoria é a boa-fé dos indivíduos que mantêm algumas relações jurídicas com as pessoas jurídicas envolvidas.

Já a quarta jornada de Direito Civil aprovou os enunciado de números 281, 282, 283 e 285, respectivamente, in verbis:

281 - Art. 50. A aplicação da teoria da desconsideração, descrita no art. 50 do Código Civil, prescinde da demonstração de insolvência da pessoa jurídica.

282 - Art. 50. 0 encerramento irregular das atividades da pessoa jurídica, por si só, não basta para caracterizar abuso de personalidade jurídica.

283 - Art. 50. É cabível a desconsideração da personalidade jurídica denominada "inversa" para alcançar bens de sócio que se valeu da pessoa jurídica para ocultar ou desviar bens pessoais, com prejuízo a terceiros.

[...]

284 - Art. 50. A teoria da desconsideração, prevista no art. 50 do Código Civil, pode ser invocada pela pessoa jurídica em seu favor. (Aguiar Junior, 2009).

Nos comentários do arti. 50 do código civil, Nelson Nery Junior, aponta o Enunciado no 284, da IV Jornada Direito Civil, como exemplo de abuso da personalidade por pessoa jurídica sem fins lucrativos, in verbis:

284 - Art. 50. As pessoas jurídicas de direito privado sem fins lucrativos ou de fins não-econômicos estão abrangidas no conceito de abuso da 
personalidade jurídica. (Aguiar Junior, 2009)

Para uma melhor compreensão do assunto, elucidativa a interpretação do dispositivo feita pelo magistério de Nelson Nery, ao afirmar que o requerente ou o membro do Ministério Público que tem que provar os requisitos.

A autorização da desconsideração da personalidade jurídica pode ser dada em qualquer tipo de processo judicial, até mesmo em Mandado de Segurança, uma vez que já existe acórdão do Superior Tribunal de Justiça, tratando do tema, in verbis:

\section{DESCONSIDERAÇÃO DA PESSOA JURIDICA EM SEDE DE MANDADO DE SEGURANÇA \\ RMS. DESCONSIDERAÇÃO DA PERSONALIDADE JURÍDICA (DISREGARD). FRAUDE. INVESTI- GAÇ̃̃O PROBATÓRIA. WRIT. VIA NÃO ADEQUADA. 1. Havendo, dentro dos limites que o mandado de segurança permite e autoriza, certeza, pelo teor do julgado recorrido, da ocorrência de fraude na venda de ações, admite-se, através do instituto da desconsideração (disregard), seja ignorada a autonomia patrimonial da pessoa jurídica.}

2. 0 acolhimento de tese em contrário, esbarra na necessidade de investigação probatória, vedada em sede de mandado de segurança.

3. Recurso ordinário improvido. (RMS 12873/SP, Rel. Ministro FERNANDO GONÇALVES, QUARTA TURMA, julgado em 02.12.2003, DJ 19.12.2003 p. 464) (Nery Junior, 2009).

Contudo, no que concerne a concessão de liminar inaudita altera pars, André Luiz Ramos diz que é possível, com base em decisão fundamentada, "segundo inequívocas provas de confusão patrimonial e constatado desvio de finalidade, com receio de dano irreparável ou de difícil reparação, já decidiu, o Tribunal de Justiça do Rio Grande do Sul" (TJRS, 2010), in verbis:

AGRAVO DE INSTRUMENTO. AÇÃO
REVOCATÓRIA. Verificando-se que a
ouvida da parte contrária com sua
citação antes do exame de liminar
poderá tornar ineficaz a medida, ou
quando a urgência indicar a
necessidade de concessão imediata
da tutela, o juiz poderá fazê-lo
inaudita altera parte, pois
preenchidos os requisitos do artigo
273 do CPC. Efeitos da
desconsideração da personalidade
jurídica estendidos ao agravante.
AGRAVO DESPROVIDO. (TJRS -
Agravo de Instrumento no
70007528458, Sexta Câmara Cívil,
Tribunal de Justiça do RS, Relator:
Cacildo de Andrade Xavier, Julgado
em 07/04/2004). (TJRS, 2010,
passim).

Portanto, a desconsideração não implica no desfazimento ou anulação do ato constitutivo da sociedade comercial, mas sim na sua ineficácia momentânea.

Nahas (2004) menciona diversos artifícios que a pessoa física pode utilizar para burlar a sociedade, tais como: o abuso de direito, excesso de poder, infração da lei ou ato ilícito que são considerados atos dos administradores. Nesses atos, não há diretamente a desconsideração, já que a responsabilidade é direta dos seus agentes. Porém, se os meios ilegais acima citados causarem prejuízos ao consumidor ou a terceiros, poderá haver a desconsideração da pessoa jurídica, quebrando-se sua autonomia patrimonial.

\section{A desconsideração da pessoa jurídica na lei ambiental}

A desconsideração da personalidade jurídica é uma doutrina que vem sendo aplicada no Brasil desde os anos 1970 do século passado, no ordenamento jurídico pátrio existe regulamentação da teoria no Código Civil, 
Código de Defesa do Consumidor, Lei Antitruste e Lei Ambiental.

A Lei no 9.605/1998 trouxe em seu art. $4^{\circ}$ a teoria da desconsideração da personalidade jurídica, in verbis:

Art. 4을 Poderá ser desconsiderada a pessoa jurídica sempre que sua personalidade for obstáculo ao ressarcimento de prejuízos causados à qualidade do meio ambiente. (Bittencourt, 2011, p. 196).

Com a entrada em vigor da Lei dos Crimes Ambientais, a doutrina da desconsideração passou a ser prevista contra os ilícitos ambientais, uma vez que a aplicação desta teoria abre a possibilidade de a justiça amenizar a fraude de pessoas que utilizam as regras jurídicas da sociedade para fugir de suas obrigações ou mesmo agir fraudulentamente (Dias, 2013, p. 101).

Este dispositivo encontra-se em consonância com o art. 225 Constitucional, que prevê que, no caso de crimes ambientais, o bem tutelado é o meio ambiente, que é considerado como bem de uso comum do povo, portanto, é um bem difuso e de interesse de todos, que deve ser defendido por todos (Silva, 1995, p. 312).

A lei inovou com a previsão, no artigo segundo, da possibilidade de condenação do diretor, administrador, membro de conselho e órgão técnico, auditor, gerente, preposto ou mandatário de pessoa jurídica que, sabendo da conduta criminosa de outrem, elencada na lei, deixar de impedir sua prática, quando podia agir para evitá-la. Trazendo também no artigo terceiro a possibilidade de responsabilização administrativa, civil e penal das pessoas jurídicas por infrações cometidas por decisão de seu representante legal ou contratual, ou de seu órgão colegiado no interesse ou benefício da sua entidade (Di Pietro, 1992).

Pelos dispositivos legais em comento, a teoria da "desconsideração da pessoa jurídica” será aplicada sempre que a pessoa jurídica praticar algum ilícito ambiental, respondendo juntamente com a pessoa física responsável, dentre as descritas no artigo segundo da lei ambiental, causadora do dano, pelos atos praticados por esta em seu nome. Da mesma maneira, o cidadão que tentar fraudar a lei se escudando por trás de uma sociedade, com o fim de praticar atos delituosos contra a qualidade do meio ambiente natural, artificial, cultural e do trabalho, deverá responder administrativa, civil e penalmente pelos seus atos (Barroso, vol. 317).

Quanto à indenização na esfera civil, a responsabilidade é objetiva, bastando ser averiguado o dano e a autoria para gerar a obrigação de reparar, uma vez que a lei ambiental não excluiu a responsabilidade na esfera civil - conforme previsão do art. 225, § 3oㅡ da Constituição Federal. Neste sentido, a Lei no 6.938/1981, que institui a Política Nacional do Meio Ambiente, regulamenta o tema, com previsão no art. $14, \S 1$ o.

O Superior Tribunal de Justiça já se manifestou pela possibilidade de aplicação da teoria da personalidade jurídica nos crimes ambientais, in verbis:

CRIMINAL. CRIME AMBIENTAL PRATICADO POR PESSOA JURÍDICA. RESPONSABILIZAÇÃO PENAL DO ENTE COLETIVO. POSSIBILIDADE. PREVISÃO CONSTITUCIONAL REGULAMENTADA POR LEI FEDERAL. OPÇÃO POLÍTICA DO LEGISLADOR. FORMA DE PREVENCẼO DE DANOS AO MEIO-AMBIENTE. CAPACIDADE DE AÇÃO. EXISTÊNCIA JURÍDICA. ATUAÇÃO DOS ADMINISTRADORES EM NOME E PROVEITO DA PESSOA JURÍDICA. CULPABILIDADE COMO RESPONSABILIDADE SOCIAL. CORESPONSABILIDADE. PENAS ADAPTADAS À NATUREZA JURÍDICA DO ENTE COLETIVO. RECURSO PROVIDO. Processo REsp 564960/SC; RECURSO ESPECIAL 2003/01073684 Relator(a) Ministro GILSON DIPP (1111). Órgão Julgador T5 - QUINTA TURMA. Data do Julgamento 02/06/2005. Data da Publicação/ 
Fonte DJ 13.06.2005 p. 331 RDR vol. 34 p. 419.

Concluindo, o cidadão que se utilizando de uma sociedade empresária, ao cometer uma ação ou omissão dolosa ou culposa que cometa não só um crime ambiental mas também um dano civil, poderá, sob o prima da teoria da disregrad doctrine, responder diretamente pelos danos gerados (Albergaria, 2005, p. 145).

\section{Aplicação da teoria nos crimes ambientais: o caso do Rio Doce}

No caso do Rio Doce o embate
surge em quem arcará com o ressarcimento das ações emergenciais e de reparação de danos, já que o controle da Samarco, encontra-se com duas gigantes da mineração, a brasileira Vale e anglo-australiana BHP, em um bilhão de reais estabelece um acordo firmado com os Ministérios Públicos Federal e de Minas Gerais. O governo federal quer vinte bilhões, assim, a Advocacia Geral da União processará a Vale e Samarco para pagarem muito mais pelos danos causados (Bercovici, 2015).

0 desastre da Barragem de Fundão já é considerado o acidente industrial que ocasionou o maior impacto ambiental da história envolvendo barragens de rejeitos, com um volume total despejado de 62 milhões de metros cúbicos (Schreiber, 2015).

O Instituto Brasileiro do Meio Ambiente (IBAMA) estima que da centena de espécies de peixes do Rio Doce, dezenas podem ser extintas. A mortalidade desses peixes após o acidente chamam a atenção, espécies significativas para a sobrevivência dos habitantes de um local em que vivem da pesca (Fernandes et al., 2016).

Sobre o perigo de extinção Alexandra Aragão diz que: "a sobrevivência dessa espécie torna-se um valor jurídico fundamental que, nos conflitos ecológicos, conduzirá à prevalência desse valor ecológico sobre quaisquer outros valores humanos não vitais" (Aragão, 2006, p. 129).

O Ministério Público (MP) do Estado de Minas Gerais acusa a mineradora. Um dos promotores que investiga o caso, Carlos Eduardo Ferreira Pinto, disse ao jornal Estado de Minas que houve "negligência" por parte da empresa Samarco. Destacou que "Não há fatalidade nisso. Não podemos admitir que seja acidente um rompimento de um empreendimento de tamanha magnitude", o Ministério Público estuda quatro hipóteses: "o cumprimento das condicionantes de licenciamento da Samarco; a explosão de uma mina da Vale próximo ao local; o possível abalo sísmico; e se as obras de alteamento (elevação) da barragem causaram o rompimento" (Schreiber, 2015)

O MP está fazendo seu papel, cabendo agora, a sociedade se manifestar pela inclusão no código de mineração, da questão ambiental social.

A Constituição Brasileira adota a responsabilidade criminal das pessoas jurídicas, nos artigos 173 , § 50, e 225 , § $3^{\circ}$. A responsabilidade penal conjuntamente com a disregrad doctrine elaboraram dois instrumentos de segurança jurídica, sob a ótica dos poderosos contra os mais fracos. A pena tem dois planos: um de caráter público, com a finalidade de prevenção geral; o outro de prevenção especial não marcada pela retribuição, e sim pelo cuidado, atenção que as empresas tratarão do meio ambiente (Migliari Junior, 2004).

Shecaira (1998) defende essa evolução:

É impensável haver responsabilidade coletiva sem a co-autoria da pessoa individual, em face da relevância daquela conduta para o reconhecimento do crime da pessoa coletiva e desse co-autor para a execução do crime. Pode-se afirmar que um crime só existirá quando houver sacrifício a um bem jurídico relevante na órbita penal (Shecaira, 1998, p. 149) 
No caso da contaminação das águas do Rio Doce, o art. 6, da Lei no $8.072 / 1990$, originalmente tratava como crime hediondo, contudo, a Lei $\mathrm{n}$ 8.930/1994 exclui essa tipificação do rol da lei de crimes hediondos, o crime de poluição de águas é previsto desde o Código Penal de 1890 até os art. 270 e 271 do atual diploma criminal brasileiro (Migliari Junior, 2004).

0 crime do art. 54, da Lei $\mathrm{n}^{-}$ 9.605/1998, trata-se de um crime de dano "que resultem" ou de perigo concreto de antecipar a proteção "ou possam resultar", é um delito de perigo abstrato (Caetano, 2016).

No caso do desastre do Rio Doce, o Ministério Público denunciou 21 pessoas, seis estrangeiros, dentre a Samarco, a Vale e a BHP, por crimes ambientais.

Portanto, o estado tinha o intuito de fazer um acordo judicial com as empresas, porém, uma vez isso não ocorrendo, o governo poderá requerer o sequestro dos recursos com base no faturamento ou no lucro das corporações envolvidas, daí entra a teoria estudada nesse artigo (Bercovici, 2015).

\section{Considerações finais}

Hoje podemos dizer que a sociedade clama pela promulgação de uma lei especifica para tratar do assunto da desconsideração da pessoa jurídica. É lamentável que o Projeto de Lei $\mathrm{n}^{\circ}$ 2.426/2003 de autoria do Deputado Ricardo Fiuza não tenha sido convertido em lei.

Fato é que o ordenamento jurídico só passou a ter um dispositivo que tratasse dessa teoria em 1990, com o art. 28, do Código de Defesa do Consumidor e depois, em 1994, com o art. 18 da Lei-Antitruste. Em seguida, em 1998, veio o art. 4o, da Lei dos Crimes Ambientais (Lei no 9.605/1998). 0 mais importante texto normativo que trata do tema é o art. 50 do código civil, que só adveio tardiamente em 2002.
Entretanto, embora a situação legislativa tenha sido insuficiente aos longos dos anos, a atuação doutrinária e judicial vem, desde meados dos anos 1970, trabalhando pela integralização dessa importante doutrina.

A teoria da desconsideração da personalidade jurídica inversa tem $o$ objetivo de não considerar os efeitos da personificação para poder adentrar na responsabilidade dos sócios, os quais responderão pela atitude fraudulenta e o abuso de direito que ocultaram nas vestes da pessoa jurídica. Por isso, é também denominada como doutrina da penetração, como já explicitado no deslinde deste artigo.

Com a aplicação dessa teoria, qualquer Tribunal busca levantar o véu, ou seja, retirar a autonomia patrimonial da pessoa jurídica em questão para, então, alcançar seus bens e dificultar as fraudes e ilegalidades cometidas por seus administradores. 0 órgão Julgador não busca apenas diferenciar o patrimônio da pessoa jurídica e do sócio; perquire, de igual modo, a não consumação dessas irregularidades.

Nos termos do art. 50, do Código Civil, constatado o abuso na utilização da personalidade jurídica, através de desvio de finalidade ou confusão patrimonial, permite-se ao juiz, no caso concreto, a pedido da parte interessada (o prejudicado pela conduta ilícita) ou do Ministério Público, desconsiderar a personalidade da empresa - fazendo cessar a sua autonomia patrimonial, possibilitando a penhora de bens particulares dos membros, submetendo os sócios a um processo judicial, depois da comprovação da insolvência da pessoa jurídica. Sendo assim, a desconsideração advém do uso irregular, ou seja, da mistura de patrimônios da pessoa jurídica com o dos seus sócios.

Impende destacar que a aplicação da desconsideração inversa é muito frequente nas Varas de Fazenda Pública. Caso recorrente, objeto de vários pronunciamentos judiciais no ordenamento jurídico, dá-se quando o sócio transforma 
os bens da sociedade em bens das pessoas, com o objetivo de frustrar a execução de processos de crimes ambientais e fraudar o ressarcimento do dano.

No mais, salienta-se o ponto exorbitante do texto jurídico, qual seja, a transferência dos bens particulares dos sócios para a pessoa jurídica com objetivo de burlar a lei. Essa prática deve ser combatida pelos órgãos Julgadores através da desconsideração.

Sobre o fato analisado nesse artigo, caso os bens das controladoras da Samarco (Vale e BHP) não cheguem aos 20 bilhões pedidos. Tanto a Advocacia Geral da União que impetrou a ação, quanto o Ministério Público, como representante da tutela dos interesses difusos e coletivos, podem acionar ao juízo que imediatamente promova a desconsideração da personalidade jurídica dos sócios daquelas empresas.

Finalmente, sugerimos uma reflexão a respeito de uma possível solução. Destarte, sugere-se que, quando o cartório receber um processo de transmissão de bens de empresa para outrem, seja tido como requisito para a sua consecução a comprovação de que esta empresa não responde por nenhum processo administrativo ou criminal por dano e crimes ambientais.

Pelo acima exposto, as empresas ou indústrias em geral devem ficar abertas para com as referencias ambientais, para que possam entrar nos paradigmas com suas atividades e parques industriais respeitando os novos parâmetros mundiais da sustentabilidade, ou desenvolvimento sustentável.

\section{Conflito de interesses}

Os autores declaram não haver conflito de interesses.

\section{Referências}

Aguiar Junior, R. R. (Org). Jornada de Direito Civil. Brasilia: CJF, 2009.
Aguiar Junior, R. R. (Org). Jornada de Direito Civil. Brasília: CJF, 2003.

Aguiar Junior, R. R. (Org). Jornada de Direito Civil. Brasília: CJF, 2007.

Albergaria, B. Direito ambiental e a responsabilidade civil das empresas. Belo Horizonte: Fórum: 2005.

Aragão, M. A. S. 0 princípio do nível elevado de protecção e a renovação ecológica do direito do ambiente e dos resíduos. Coimbra: Almedina, 2006.

Barbosa, H. H.; Moraes, M. C. B.; Tepedino, G. Código civil interpretado conforme a constituição da república. 2 ed. Rio de Janeiro: Renovar, 2007.

Barroso, L. R. A proteção do meio ambiente na Constituição Brasileira. Revista Forense, v. $317,1992$.

Bercovici, G. Entrevista concedida a revista Carta Capital, São Paulo, edição n. 878, 2015. "Atitude do Estado aumenta a probabilidade de desastres como o de MG", de 19 de novembro de 2015. Disponível em: <http://www.cartacapital.com.br>. Acesso em 19 maio 2018.

Bittencourt, S. Comentário à lei de crimes contra o meio ambiente e suas sanções administrativas. 3. ed. atual e ampl. São Paulo: Fórum, 2011.

Brasil. Supremo Tribunal Federal. ADIn 3153-AgR, 12.08.04, Pertence, Inf STF 356. Disponível em: <http://www.stf.gov.br/>. Acesso em: 12 mar. 2018.

Caetano, M. A. Os delitos de acumulação no direito penal ambiental. São Paulo: Pillares, 2016.

Coelho, F. U. Manual de direito comercial. 13. ed. São Paulo: Saraiva, 2002.

Comparato, F. K. Direito empresarial. São Paulo: Saraiva, 2003.

Di Pietro, M. S. Z. Polícia do Meio Ambiente. Revista Forense, v. 317, 1992.

Dias, E. C. Direito Ambiental: no estado democrático de direito. São Paulo: Forum, 2013.

Diniz, M. H. Código civil anotado. 14. ed. São Paulo: Saraiva, 2009.

Fernandes, G. W.; Goulart, F. F.; Ranieri, B. D.; Coelho, M. S.; Dales, K.; Boesche, N.; Bustamante, M.; Carvalho, F. A.; Carvalho, D. C.; Dirzo, R.; Fernandes, S.; Galetti, P.M.; Millan, V. E. G.; Mielke, C.; Ramirez, J. L.; Neves, A.; Rogass, C.; Ribeiro, S. P.; Scariot, A.; 
Soares-Filho, B. Deep into the mud: Ecological and socio-economic impacts of the dam breach in Mariana, Brazil. Natureza \& Conservação, v. 14, n. 2, p. 35-45, 2016. https://doi.org/10.1016/j.ncon.2016.10.003

Gonçalves, C. R. Direito Civil brasileiro: direito de família. 7. ed. São Paulo: Saraiva, 2010.v. 6.

Gonçalves, C. R. Direito Civil, parte geral. 14 ed. São Paulo: Saraiva, 2007. (Coleção Sinopses Jurídicas, v. 1).

Mendonças, H. Samarco cita risco de rompimento e diz que não é hora de pedir desculpas. El Pais Brasil, 18 nov. 2015.

Migliari Junior, A. Crimes ambientais. 2. ed. Campinas: Edições Ltda, 2004.

Modena, C. M.; Heller, L. Desastre da Samarco: aproximações iniciais. Ciência e Cultura, v. 68, n. 3, p. 22-24, 2016. http://dx.doi.org/10.21800/2317-66602016 000300009

Nahas, T.C. Desconsideração da pessoa jurídica. São Paulo: Atlas, 2004.

Nery Junior, N.; Nery, R. M. A. Código Civil comentado. 7. ed. São Paulo: Revista dos Tribunais, 2009.

Ramos, A. L.S.C. Curso de Direito Empresarial: o novo regime jurídicoempresarial brasileiro. 2. ed. Salvador: Juspodivm, 2010.
Requião, R. Curso de Direito Comercial. 19. ed. São Paulo: Saraiva, 1989. v. 1.

Schreiber, M. Desastre em Mariana foi acidente ou crime? 'É precipitado avaliar', diz ministro. BBC Brasil, 11 nov. 2015. Disponível em: <http://www.bbc.com/ portuguese/noticias/2015/151110>. Acesso em: 30 maio 2018.

Serick, R. Aparência y realidad em las sociedades mercantiles, Barcelona: Ariel, 1958.

Shecaira, S. S. Responsabilidade penal das pessoas jurídicas. São Paulo: Revista dos Tribunais, 1998.

Silva, J. A. Direito Ambiental Constitucional. 2. ed. São Paulo: Malheiros, 1995.

STJ-Superior Tribunal de Justiça. Órgão Julgador T5-Quinta Turma. Data do Julgamento 02/06/2005. Data da Publicação/Fonte DJ 13.06.2005, p. 331. RDR vol. 34, p. 419.

Tepedino, G. (Coord.). A parte geral do novo Código Civil: estudos na perspectiva civilconstitucional. 3. ed. rev. Rio de Janeiro: Renovar, 2007. 